\title{
RESTAURACIÓN DE LA IGLESIA VISIGODA DE SANTA LUCÍA DEL TRAMPAL, ALCUÉSCAR (EXTREMADURA-ESPAÑA)
}

\author{
(RESTORATION OF THE VISIGOTHIC CHURCH OF SANTA LUCÍA DEL \\ TRAMPAL, ALCUÉSCAR-EXTREMADURA-SPAIN)
}

\author{
Antonio Almagro Gorbea, Dr. Arquitecto \\ Escuela de Estudios Árabes. CSIC, Granada \\ Leandro Cámara Muñoz y Pablo Latorre González-Moro, Arquitectos
}

Fecha de recepción: $t-1 \mathrm{III}-93$

$128-47$

\begin{abstract}
RESUMEN
La restauración de la iglesia visigoda de Santa Lucia del Trampal ha constituido una experiencia stumamente interesante como proyecto integrado de restauración e imestigación histórica y arqueológica. Tal carácter ha condicionado de forma especial, no sólo la metodología, sino también los criterios y por tanto los resultados. Necesidades de tipo estructural junto con las aportaciones de la propia investigación han sido determinantes en la elección de las soluciones formales y constructivas, dentro de un respeto a los conceptos de imagen $y$ del espacio originales y a una fácil identificación de la aportación actual. Esta se' ha individualizado básicamente mediante el uso de materiales y detalles constructivos no tradicionales en aquellas zonas ay a definición entra dentro del campo de la hipótesis, y con materiales y técnicas originales en donde sólo se trataba de reintegrar partes perdidas cuya forma y materiales cran perfectamente conocidos.
\end{abstract}

\section{SUMMARY}

The restoration of the Visigothic church of Santa Lucia del Trampal has been an extremely interesting experience both as an integrated restoration project and a historical and archeological rescarch. This kind of character further conditioned in a special way, not only the methodology, but also the criteria and, consequently, the results. Structural necessities together with the contributions of the investigation have been determinant in choosing formal and constructive solutions, always respecting the concepts of the original image and space as well as an easy identification of the contemporary contribution. The latter has been individualized basically through the use of materials and constructive details not traditional in those areas whose definition belongs to the field of hypothesis, and with original materials and techniques in places where it was only necessary to reintegrate the lost parts whose form and materials were perfectly known.
La iglesia de Sta. Lucía del Trampal se encuentra en la ladera del pico del Centinela o sierra del Monesterio, extremo oriental de la sierra de S. Pedro, en una situación centrada entre Trujillo, Cáceres y Mérida. Se accede a ella por un camino cómodo desde el cercano pueblo de Alcuéscar, a cuyo término pertenece. La situación geológica de la iglesia, en una zona de contacto entre las "tierras pardas", los granitos y las pizarras. ha dado lugar a la existencia de una copiosa fuente y un yacimiento de mineral de hierro en sus inmediaciones. El Trampal se sitúa en las cercanías del camino romano de La Plata que pasa al otro lado del cerro del Centinela.

Cuando se produjo el hallazgo e identificación de la iglesia de Santa Lucía como obra visigoda, posible mente del s. VII, su estado de conservación hay que definirlo como de total ruina y abandono. Al ábside central. que aún había sido utilizado para el culto en romerías hasta hacía unos anoos, se llegaba a través del aula por un hueco abierto en el muro occidental de ésta. El hueco del cimborrio central carecía de cubrimiento y la cubierta del aula había desaparecido no quedando más que los arcos diafragma tardomedievales. Las puertas primitivas del aula estaban tapiadas. no existiendo más acceso que el antes mencionado.

Los extremos del crucero, separados de la parte central por muros que tapiaban los arcos perpianos, presentaban también un aspecto ruinoso y su interior estaba lleno de escombros. En el lado norte, una 


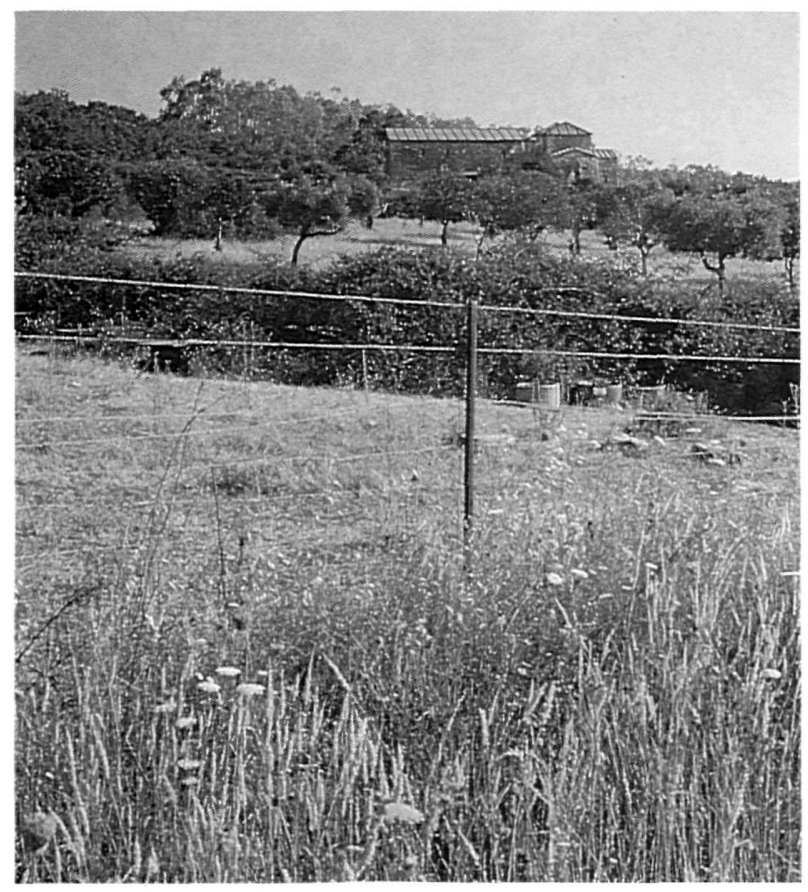

Vista de la iglesia y su entorno.

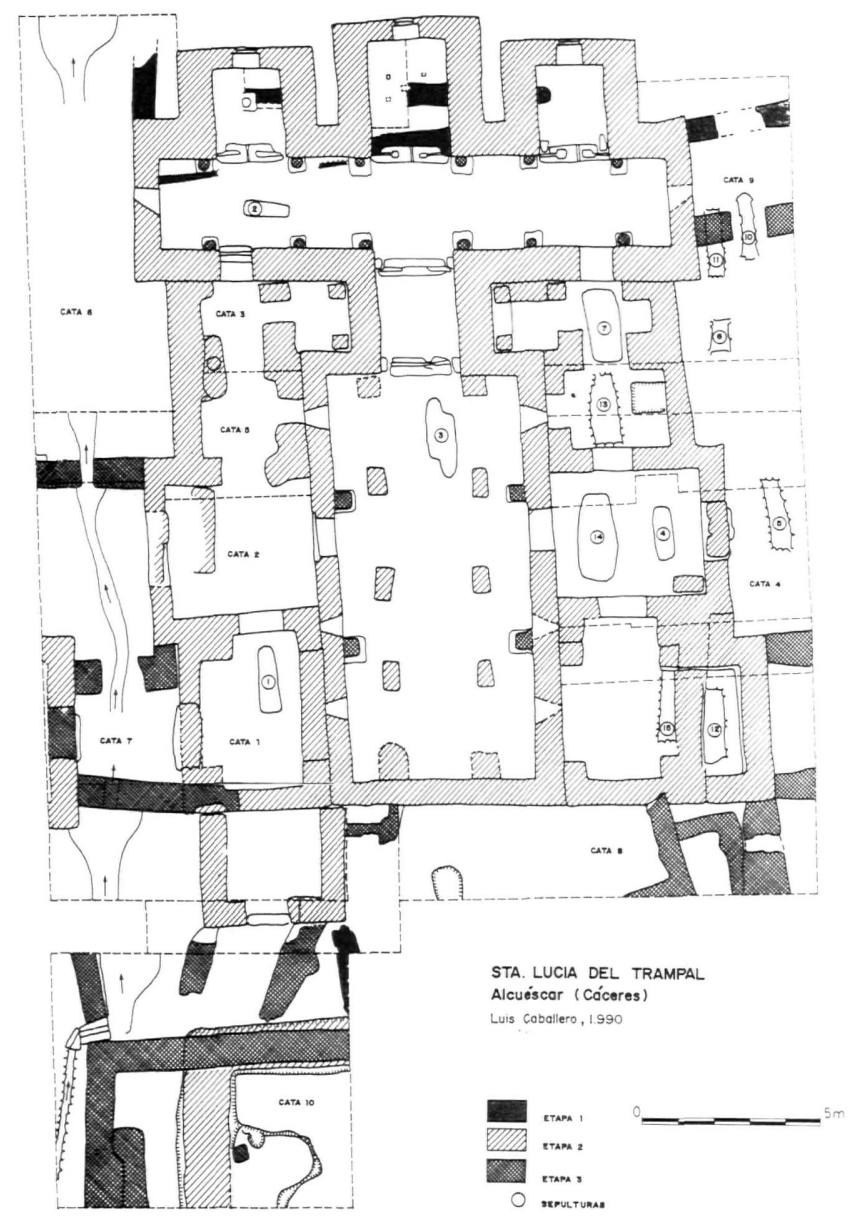

Plano esquemático de Sta. Lucia y habitaciones de su entorno. pequeña casa se había construido entre el extremo del crucero y el muro más occidental del pórtico de ese lado que aún se conservaba con su arco tapiado. Exteriormente todos los muros se veían con las zonas superiores reconstruidas generalmente con fábricas de pésima calidad que habían sustituido a partes anteriormente arruinadas o que simplemente servían para enrasar con el nivel de arranque de la cubierta. Finalmente, el muro meridional del aula presentaba un acusadísimo desplome, provocado por el empuje de los arcos diafragma del aula que igualmente estaban profundamente deformados por falta de contrarresto.

Las primeras actuaciones que se realizaron en el monumento fueron de documentación. Consistieron en el levantamiento fotogramétrico de los exteriores y de la zona del aula, realizado por el Instituto Geográfico Nacional de Madrid, que fue completado en el verano de 1986 con el equipo del gabinete de Fotogrametría del Instituto de Conservación y Restauración de Bienes Culturales del ministerio de Cultura.

Inicialmente se aprobó una pequeña obra de consolidación de urgencia, financiada por el ministerio de Cultura y dirigida por el arquitecto J. García Collado. Se demolieron algunas zonas ruinosas como los tejados y parte de los muros de la vivienda adosada y los pequeños muros con forma de piñón levantados sobre los arcos diafragma del aula. Estos arcos se trasdosaron con una estructura de hormigón armado. También se construyeron dos pequeños contrafuertes de ladrillo, con carácter provisional, para contrarrestar el vuelco del muro meridional del aula.

El hecho de encontrarnos frente a un edificio de una época de la que conocemos escasas construcciones y que no había sido alterado ("restaurado") recientemente, nos impuso actuar sobre él con la idea principal de que interveníamos sobre un documento histórico y no sólo sobre un edificio con evidentes valores artísticos. Aunque la solución final de recuperación del monumento tenía que ser eminentemente arquitectónica, los valores históricos imponían una metodología de absoluto rigor para la recuperación de todo testimonio que acrecentara nuestro mejor conocimiento del edificio y consecuentemente de la época en que el mismo fue construido.

Por otro lado, el carácter de elemento singular en su época y en el conjunto de la historia de la arquitectura, que a todas luces se vislumbraba en él, nos exigían que no sólo el estudio y la restauración fueran rigurosos, sino que, en la medida de lo posible, el 

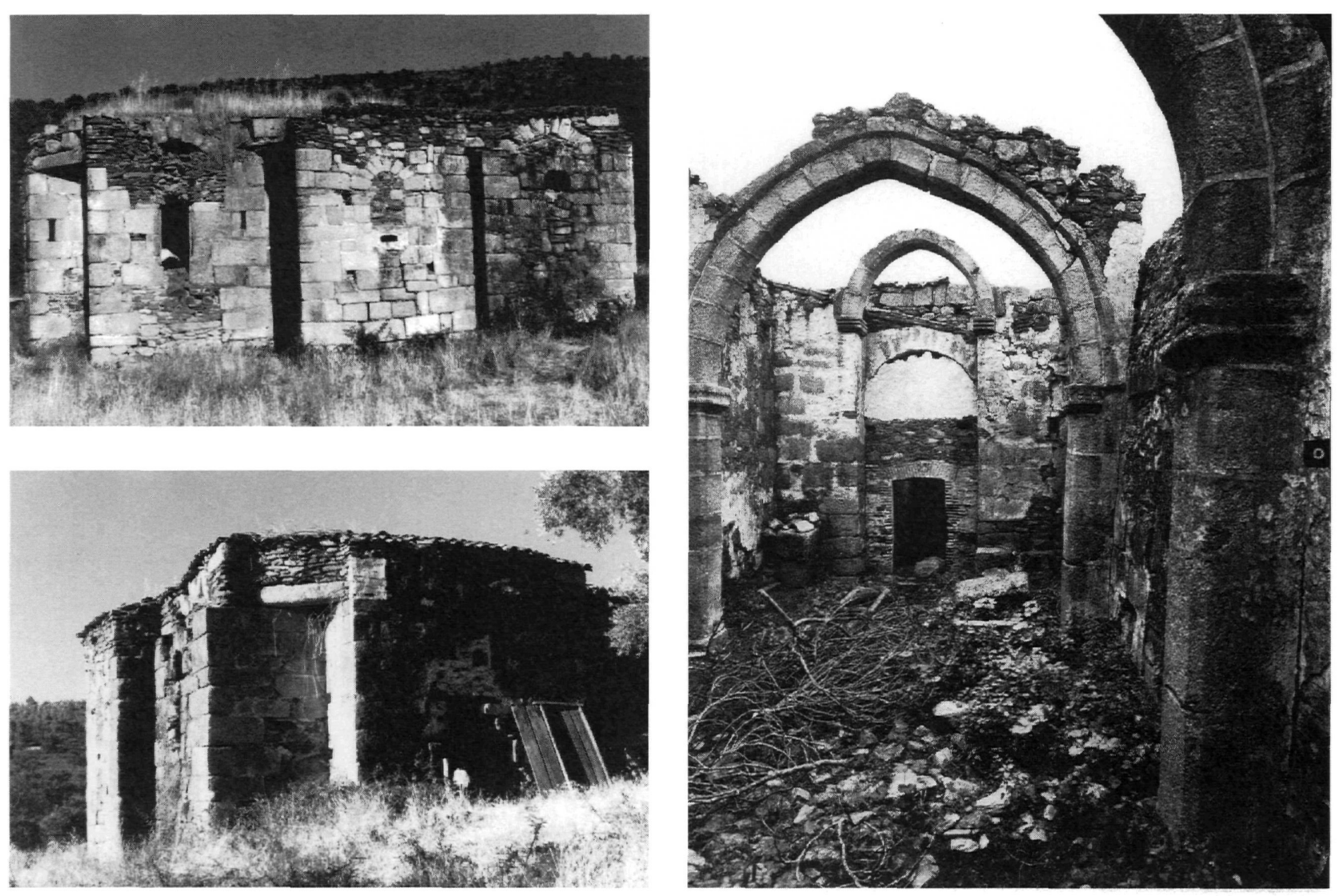

Cabecera de la iglesia antes de la restauración

El aula antes de la restauración

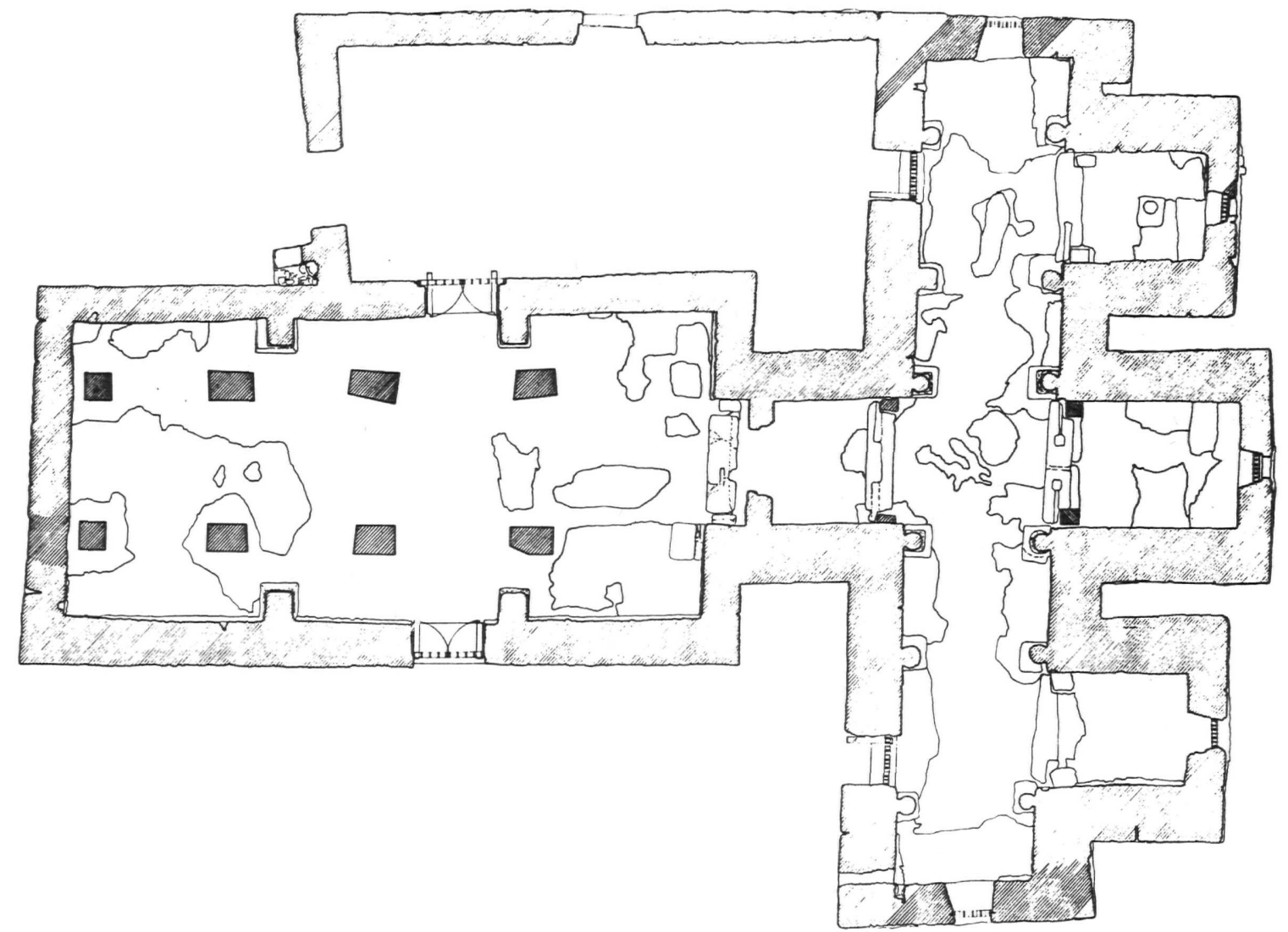

Planta de la iglesia 


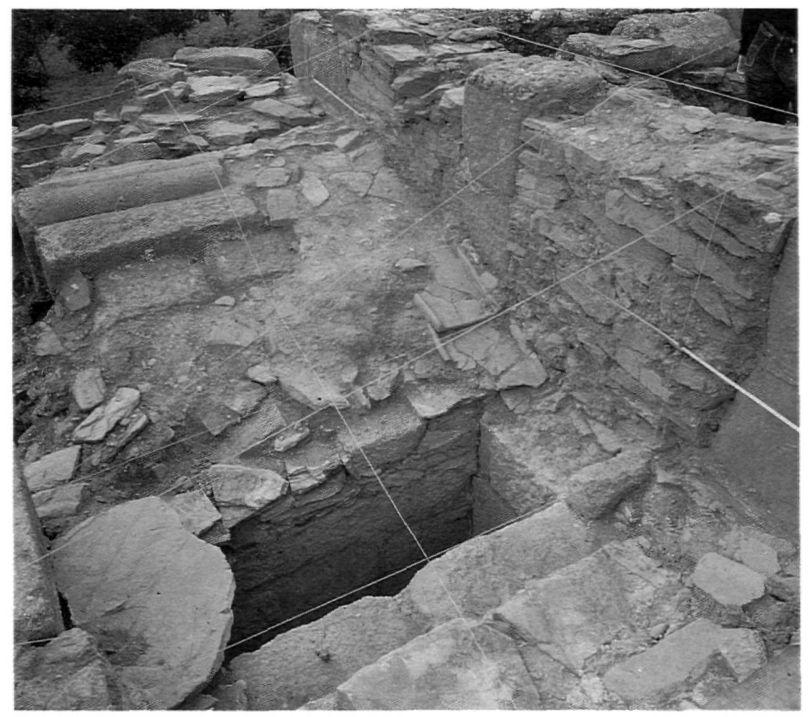

La cubierta de la cabecera y los cimborrios durante la excavación

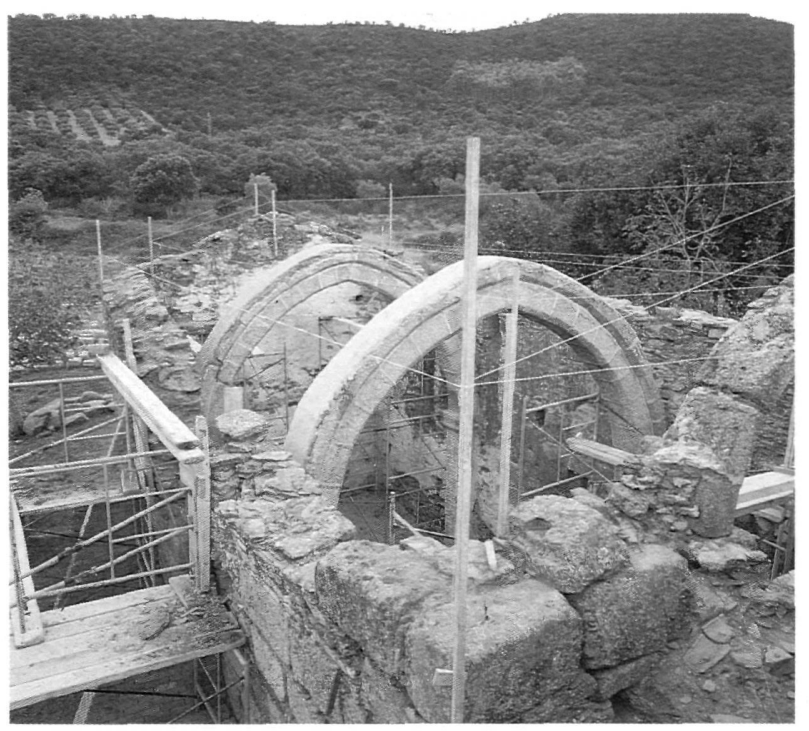

Replanteo de la cubierta del aula.

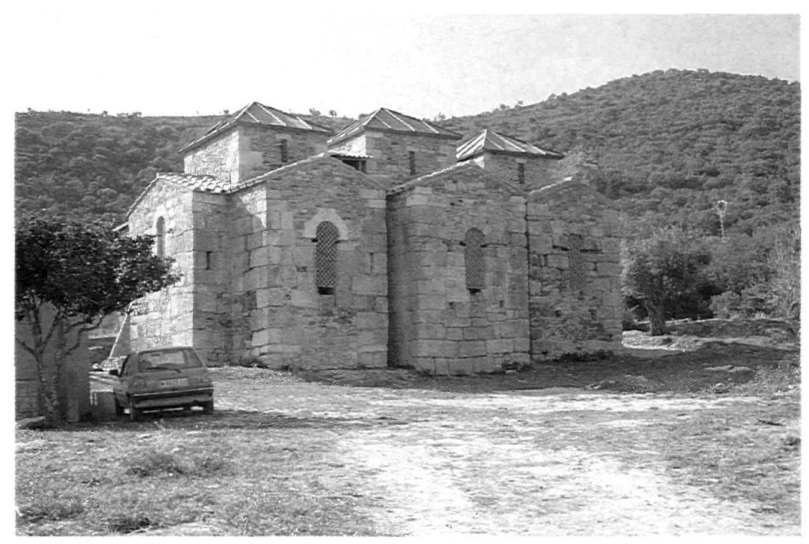

La cabecera después de la restauración rigor de la intervención restauradora quedara visible en el propio edificio a fin de que su lectura pudiera hacerse directamente y sin la ayuda de la publicación en la que evidentemente debía darse a conocer hasta el último detalle de lo hallado y lo realizado.

El criterio principal de la restauración fue el de devolver al edificio, en lo posible, su aspecto volumétrico y espacial originales. Este objetivo debía realizarse atendiéndose a otros criterios también primordiales que vamos a enumerar.

En primer lugar, todo lo que fuera preciso añadir, debía quedar perfectamente identificable. Diversos sistemas se han utilizado en otros casos para ello: paramento nuevo rehundido respecto al original, material distinto en las partes nuevas o marcar con una línea hecha con pizarras o fragmentos de teja el contacto entre ambas fábricas. La existencia en la fábrica de diversos materiales (granito, esquisto y ladrillo) nos indujo a no introducir un nuevo material que podía provocar más confusión que claridad en la identificación de lo reconstruido. La irregularidad de la fábrica y los desplomes que presentaba tampoco hacían a nuestro entender aplicable el criterio de rehundir los paramentos nuevos. Decidimos marcar la línea de contacto de las fábricas nueva y vieja, para lo que ni la pizarra ni la teja nos parecieron materiales adecuados porque la pizarra no se diferenciaba de los esquistos y la teja podía confundirse con hiladas de ladrillo originales que existían en los muros y, además, resulta más difícil de colocar. Por ello, finalmente decidimos colocar una chapa de cobre, apenas sobresaliente, en la junta. Este material se identifica perfectamente en una visión cercana, pero pasa totalmente desapercibido en una visión lejana de conjunto.

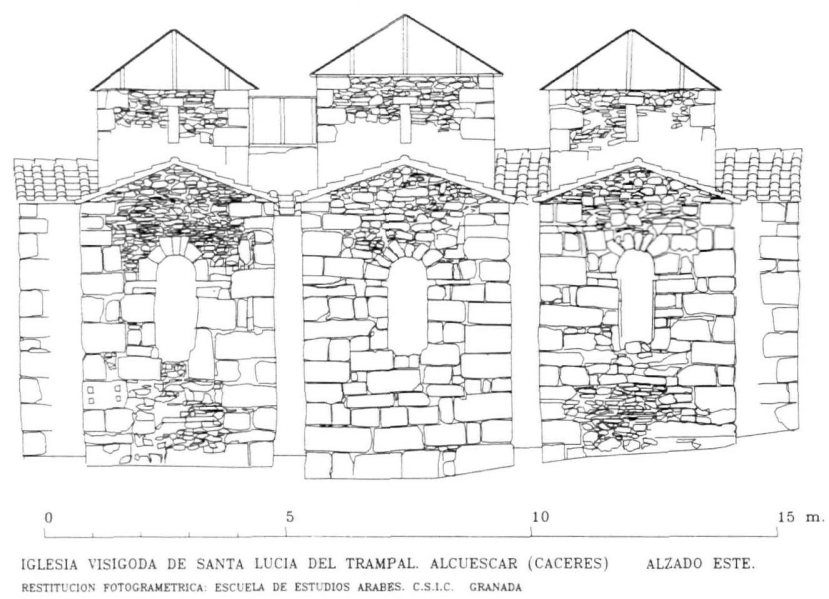



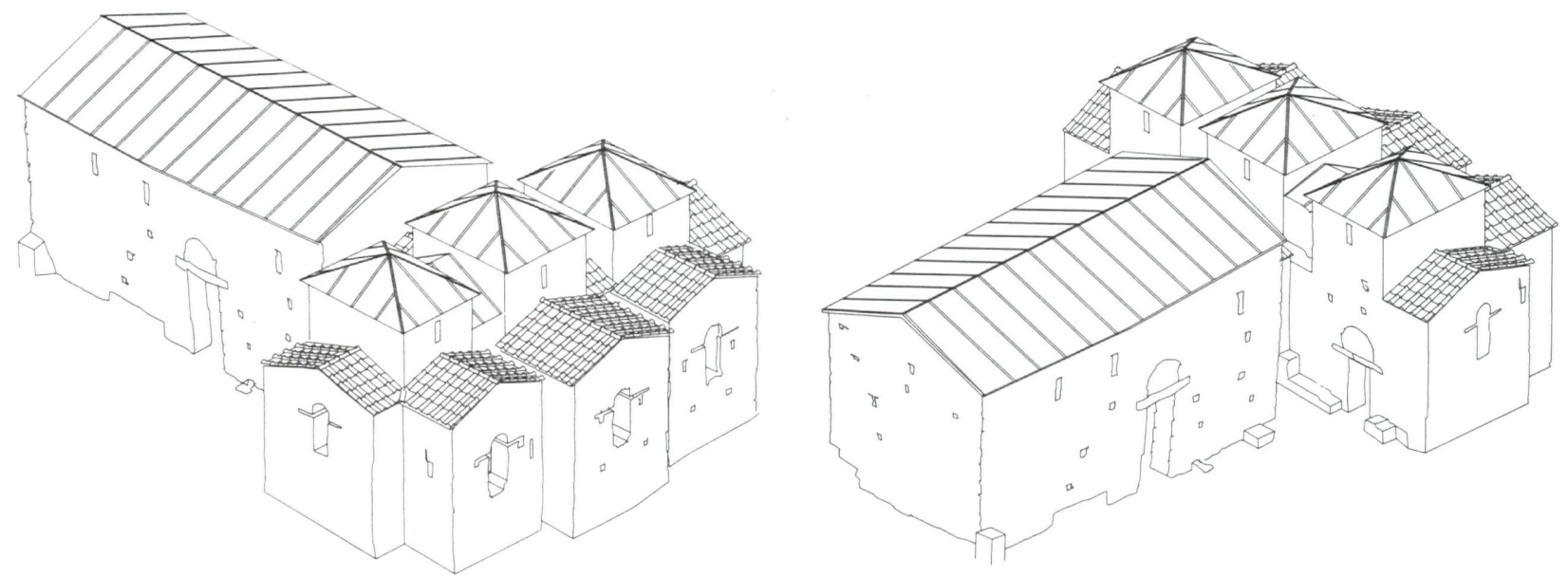

Isométrica de la iglesia

Otro de los criterios, a nuestro entender importante, era mantener una homogeneidad en el aspecto general del monumento, evitando la introducción de elementos fuertemente disonantes que alteraban los valores estéticos y ambientales originales del mismo. No basta con que la intervención sea respetuosa desde el punto de vista histórico con el monumento, permitiendo que se identifique todo lo añadido. Es imprescindible preservar igualmente los valores estéticos y espaciales originales que forman parte también del legado histórico. Un criterio también importante ha sido el respeto a todas las transformaciones que hayan supuesto una aportación histórica o esté- tica de cualquier época y que, de por sí, no supongan un menoscabo grave para los valores originales sin que en contrapartida aporten otros valores sustanciales.

La intervención debía finalmente tener un cierto carácter utilitario y didáctico, no yendo más allá de lo estrictamente necesario pero garantizando una adecuada conservación del edificio y la comprensión del mismo por parte de sus visitantes. También se contempló su utilización ocasional para el culto y, en todo caso, como obra ilustrativa de una época y un estilo.

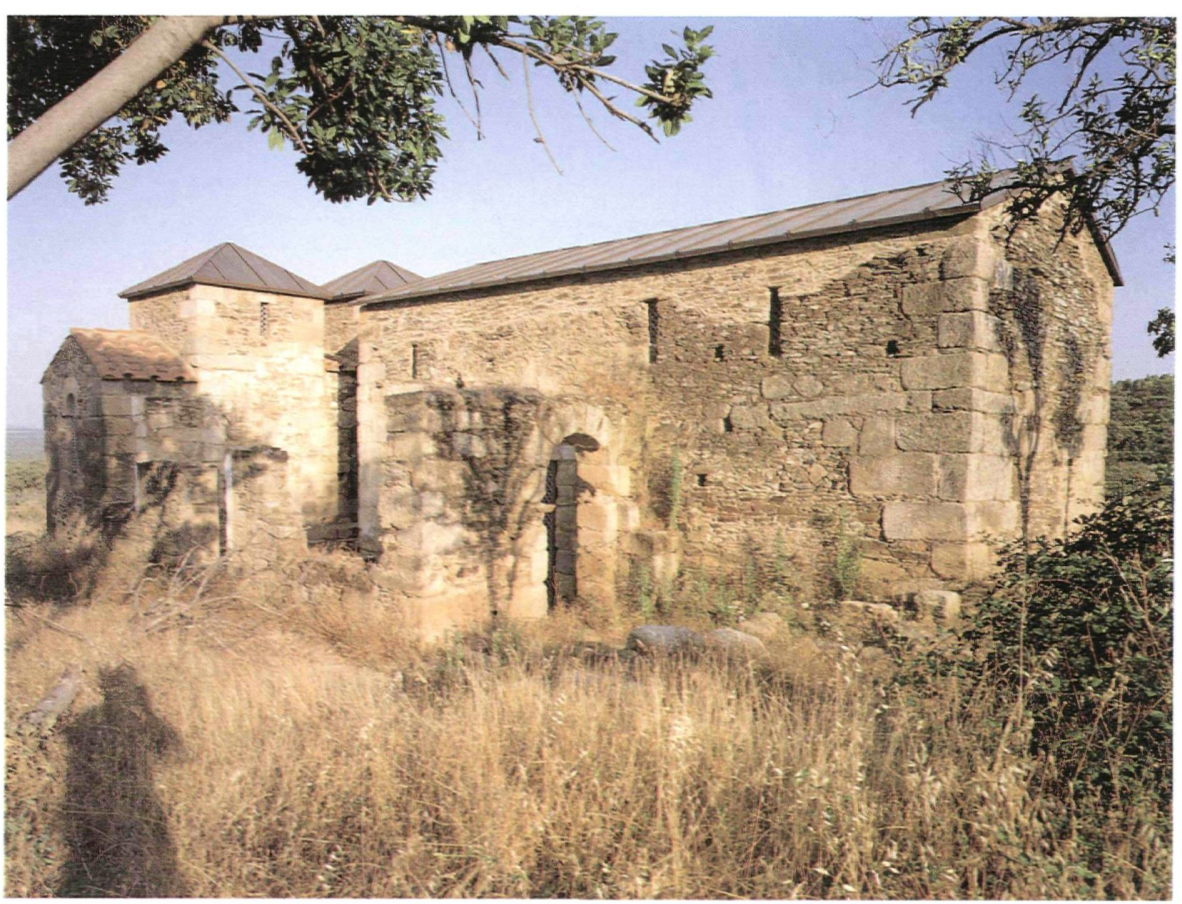

La iglesia desde el norte. 
En el año 1986 redactamos un primer proyecto de restauración muy indefinido en cuanto a su concreción formal, pero cuya finalidad teníamos bien clara. Resultaba imprescindible realizar una investigación completa del edificio, con un carácter eminentemente arqueológico del que tenía que resultar el modo en que la iglesia debía ser completada, a fin de poderla dejar cubierta. El objetivo final de esta primera actuación era dejar las estructuras de la iglesia consolidadas y, de ser posible, dejar definidas, aunque sin acabado definitivo, la forma de las cubiertas de las zonas abovedadas.

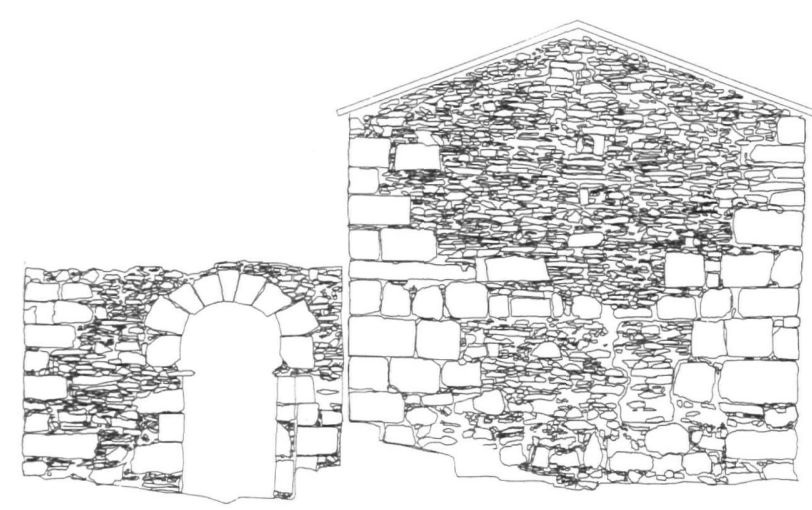

Alzado oeste
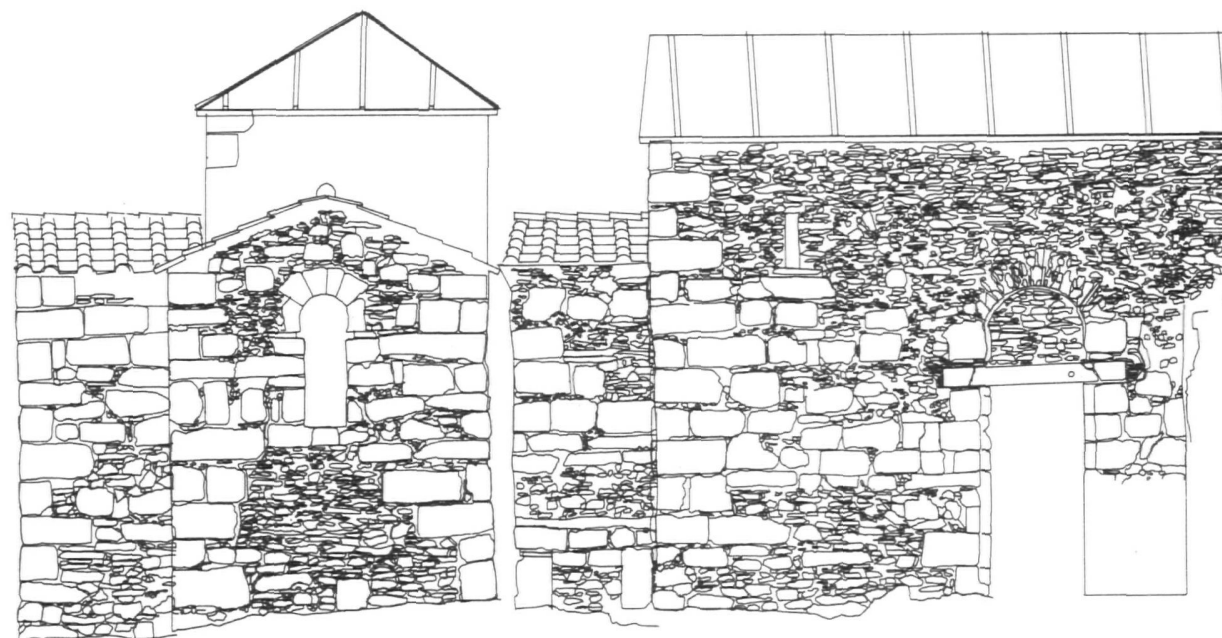

IGLESIA VISIGODA DE SANTA LUCIA DEL TRAMPAL. ALCUESCAR (CACERES)

RESTITUCION FOTOGRAMETRICA: ESCUELA DE ESTUDIOS ARABES. C.S.I.C. GRANADA.

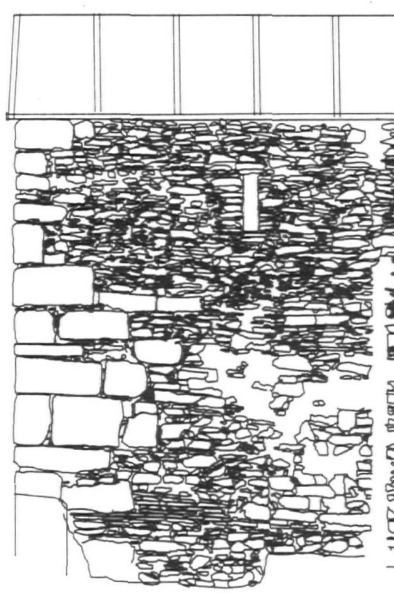

0
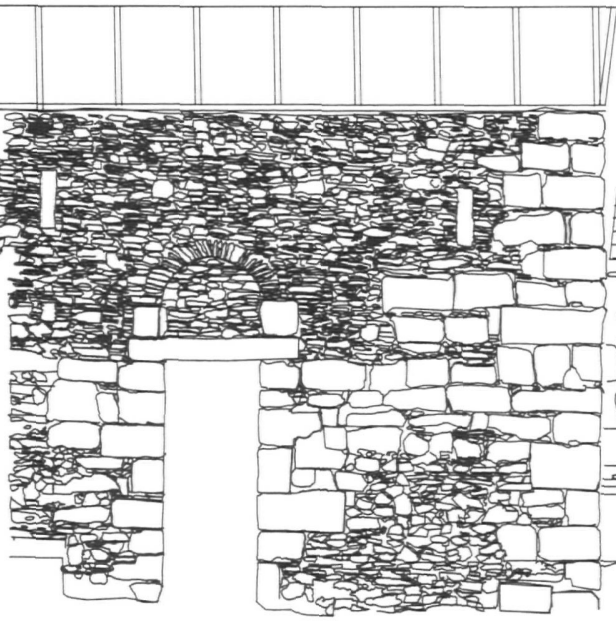

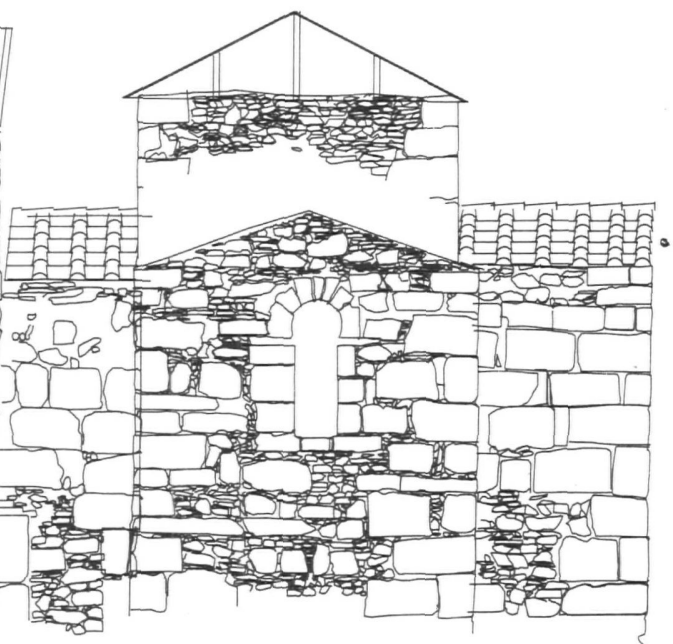

Alzado sur

$15 \mathrm{~m}$.

IGLESIA VISIGODA DE SANTA LUCIA DEL TRAMPAL. ALCUESCAR (CACERES)

RESTITUCION FOTOGRAMETRICA: ESCUELA DE ESTUDIOS ARABES. C.S.I.C. GRANADA. 


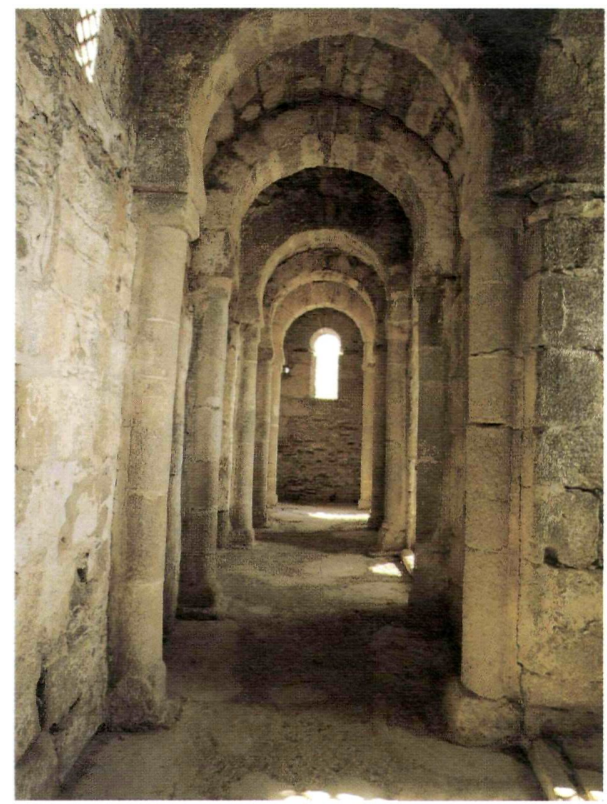

Vista del crucero desde el sur.

Esta etapa se realizó con una presencia más asidua del equipo arqueológico, que dirigió directamente el desmontaje y excavación de la cubierta existente sobre las bóvedas del crucero y los ábsides. Esta actuación resultó crucial para la definición de la operación de completar y fijar la forma volumétrica que iba a tomar la parte más vistosa e interesante de la iglesia. Se descubrió el nivel del tejado primitivo de los ábsides merced al hallazgo in situ de una tegula y fragmento de otro conservados en la vertiente norte del ábside meridional. Gracias a este hallazgo pudimos conocer la línea de coronamiento de los muros, la pendiente de las cubiertas y el material con que estaban formadas.

También se procedió a demoler las estructuras tardías que habían subdividido y por tanto transforma-

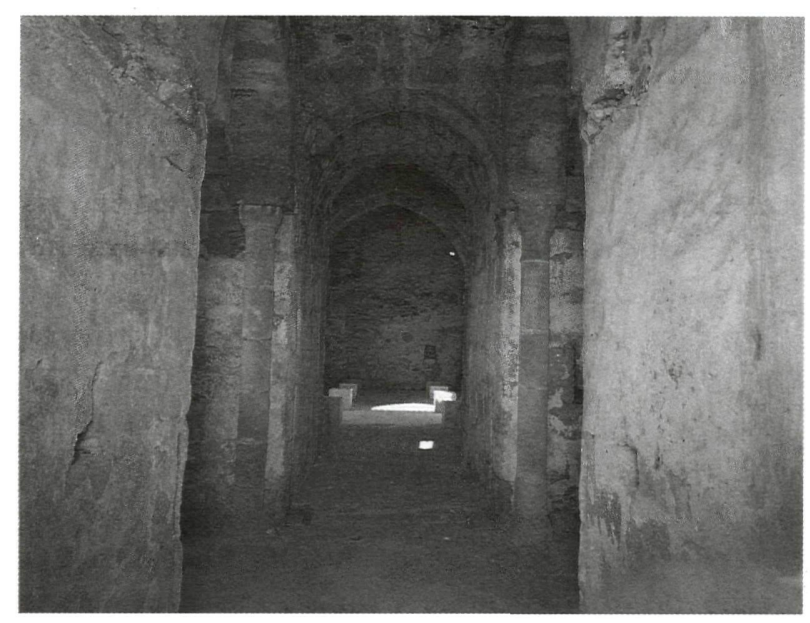

La nave desde el ábside central.

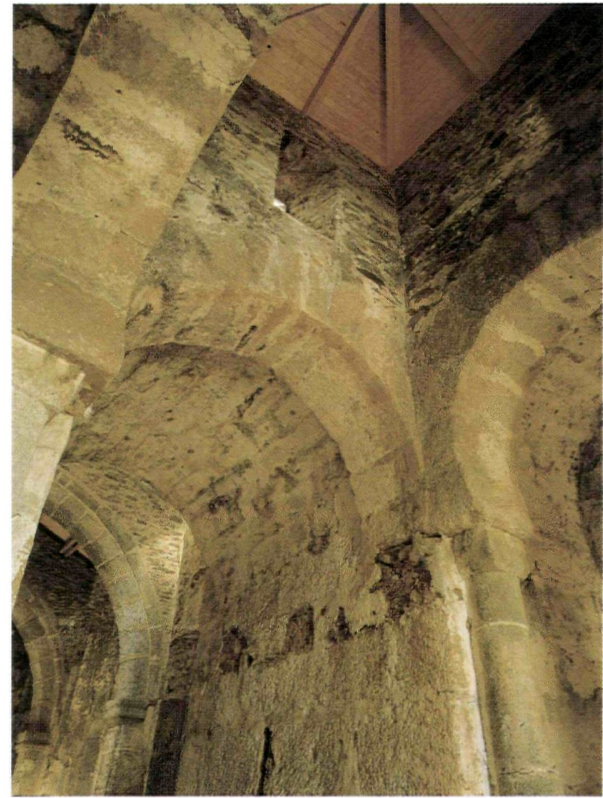

Cimborrio central.

do el primitivo espacio interior. Se abrieron las puertas del aula y del crucero, se derribaron los muros que dividían el crucero y la pared con que se había separado el ábside y el tramo central de la nave respecto del aula. Gracias a esto pudimos ya tener una impresión visual del espacio primitivo de la iglesia y comprender mejor las transformaciones antiguas del edificio. La excavación interior puso de manifiesto el nivel y la forma del pavimento, que se conservaba en amplias zonas de la iglesia y, sobre todo, permitió conocer la forma primitiva del aula, con su organización en tres naves y su probable estructura de cubierta en madera.

Una de las operaciones más delicadas fue la demolición de las zonas recrecidas de los muros, hasta dejar sólo las partes originales visigodas. En general,

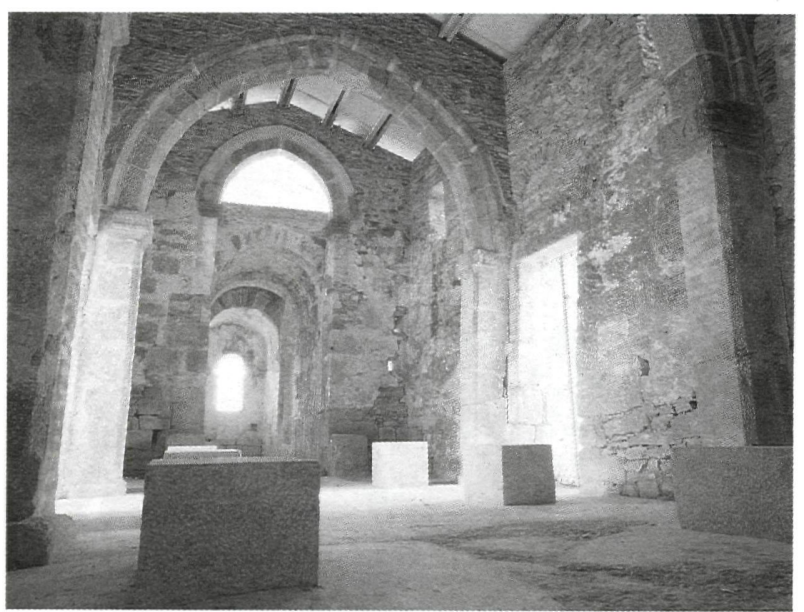

Vista del aula desde los pies de la iglesia. 
estas fábricas añadidas eran de mala calidad. En las zonas de los ábsides habían sobrepasado el nivel primitivo de remate de los muros. En el muro sur del aula, habían sustituido a zonas arruinadas seguramente por efecto del desplome. En esta zona, la eliminación de estas fábricas permitió la disposición de un atado de hormigón armado en la parte alta del muro con anclajes hacia abajo, que da mayor cohesión a esta pared que presenta un vuelco importante.

El desescombro de la cubierta puso a la vista que los cimborrios constituían cuerpos exentos y sobresalientes respecto al crucero y los ábsides. Por ello se recrecieron hasta una altura cuya fijación no tiene ninguna base científica en qué apoyarse al estar los tres desmochados. El criterio seguido fue puramente visual, buscando que existiera un equilibrio de formas y volúmenes especialmente desde la perspectiva oriental, en que el terreno desciende y se observa la cabecera de la iglesia desde un punto más bajo. En el cimborrio meridional quedaban los restos inferiores de dos ventanas en forma de aspillera, semejantes a las conservadas en el aula. Las ventanas se abren hacia el este y el oeste. Con esta pauta se dispusieron ventanas semejantes en los demás cimborrios.

Al terminar esta fase, la iglesia había recuperado la forma de sus estructuras "murarias" y quedaba con- solidada. Las bóvedas de los ábsides y el crucero se remataron con pendientes de mortero listas para recibir el material definitivo de cubierta. El aula y los cimborrios quedaron sin cubrir hasta la siguiente fase de la obra.

Al concluir la primera fase de la restauración, el monumento había cambiado notablemente en su aspecto; se habían puesto a la luz partes sustanciales del mismo y hecho desaparecer los aditamentos que impedían o alteraban la visión y comprensión del espacio y la volumetría. Por ello se consideró necesario realizar una segunda fase de documentación en donde quedara recogida la forma real del edificio tal y como iba a quedar tras la restauración, y en la que se registrara qué partes eran originales y cuáles no, puesto que en la primera planimetría realizada se dibujaron zonas de los muros que habían sido desmontadas y reconstruidas de nuevo. La documentación se realizó mediante fotogrametría para los exteriores y con métodos manuales en el interior, en donde los cambios habían sido menores. Para la realización de esta nueva documentación se utilizó el equipo de fotogrametría de nueva adquisición en la Escuela de Estudios Árabes (CSIC) de Granada. Al utilizar un restituidor analítico, toda la medición quedó almacenada en forma digital, permitiendo su posterior transformación sobre un programa de CAD.

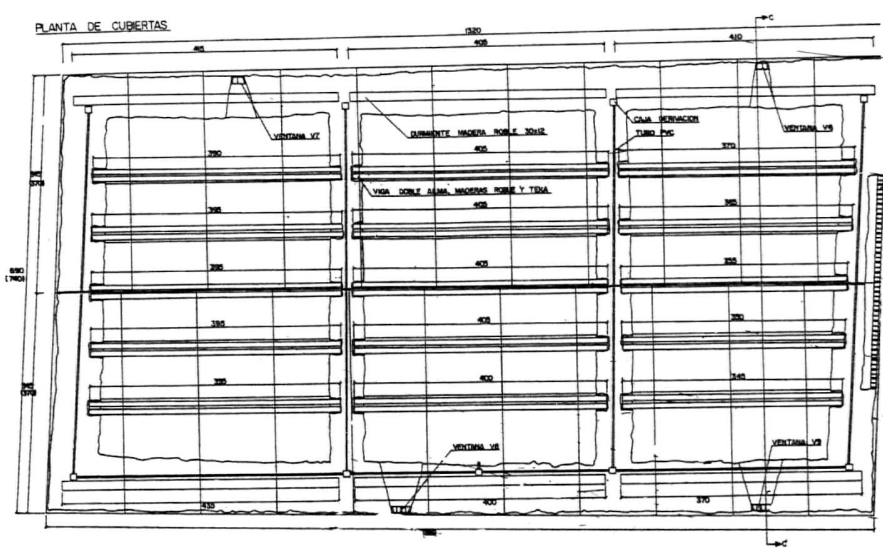

Planta de la nueva estructura de cubierta

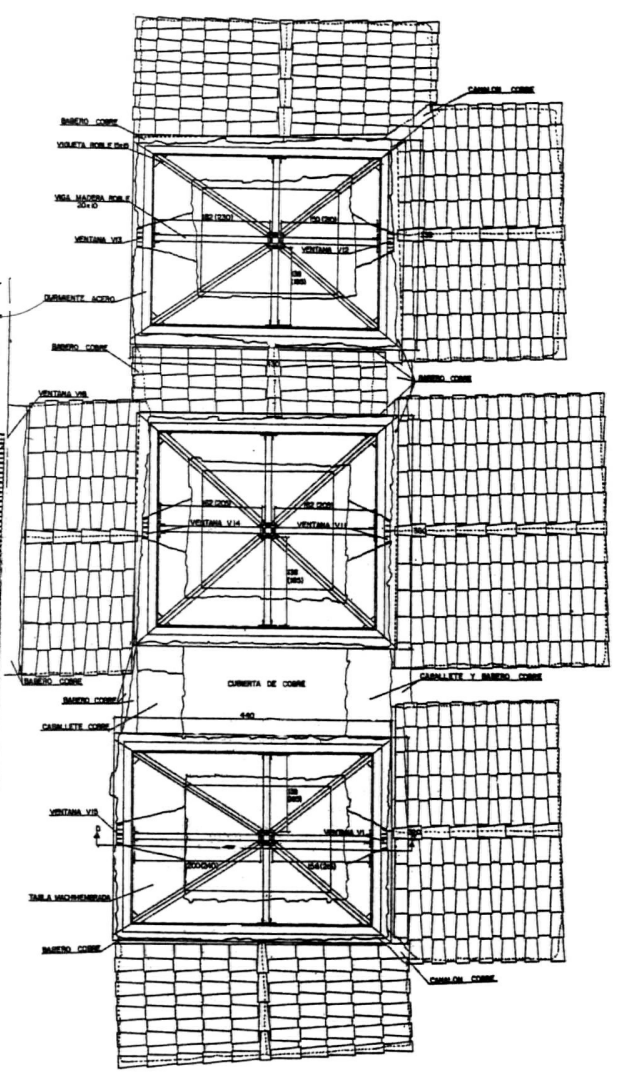


La segunda fase de la obra se planteaba ya con decisiones de diseño respecto a elementos que había que introducir, y que no correspondían ni en la forma ni en los materiales a los originales. El tema fundamental era la cobertura del aula. En esta zona, la estructura visigoda con disposición de tres naves separadas por arquerías sobre pilares rectangulares, había sido destruida en época medieval y sustituida por una disposición estructural totalmente distinta. Las naves visigodas debieron cubrirse con estructura lígnea de cerchas y correas en la nave central y, seguramente, con armadura de colgadizo en las laterales. Al desaparecer las arquerías, en época tardomedieval se creó un espacio unitario cuya cubierta se realizó mediante dos arcos diafragma de cantería sobre los que apoyaban correas. Esta estructura, a falta de los elementos lígneos, se conservaba íntegra, con la salvedad de que al faltar en el lado sur el pórtico y no existir por tanto ningún elemento de contrarresto al empuje de los arcos diafragma, se produ- jo un vuelco significativo en el del muro meridional del aula.

Tras desestimar el rehacer la estructura visigoda original, que hubiera supuesto eliminar los arcos tardomedievales, y para la que además no había datos ciertos suficientes, decidimos adoptar una solución acorde con el sistema de cubierta posterior. Pero ello suponía poner en carga los arcos diafragma y provocar de nuevo empujes sobre los muros laterales. Frente a este problema optamos por una solución distinta a la tradicional y que fuera lo más liviana posible. Diseñamos una estructura de cubierta a base de correas apoyadas en los arcos diafragma, formadas por dos tablones unidos por chapones y tornillos. Sobre estas correas va apoyado un tablero contrachapado y sobre éste una chapa de cobre con la solución clásica de empalme de las piezas mediante berenjenos con los consiguientes plegados de los bordes de las chapas. En un principio se pensó en

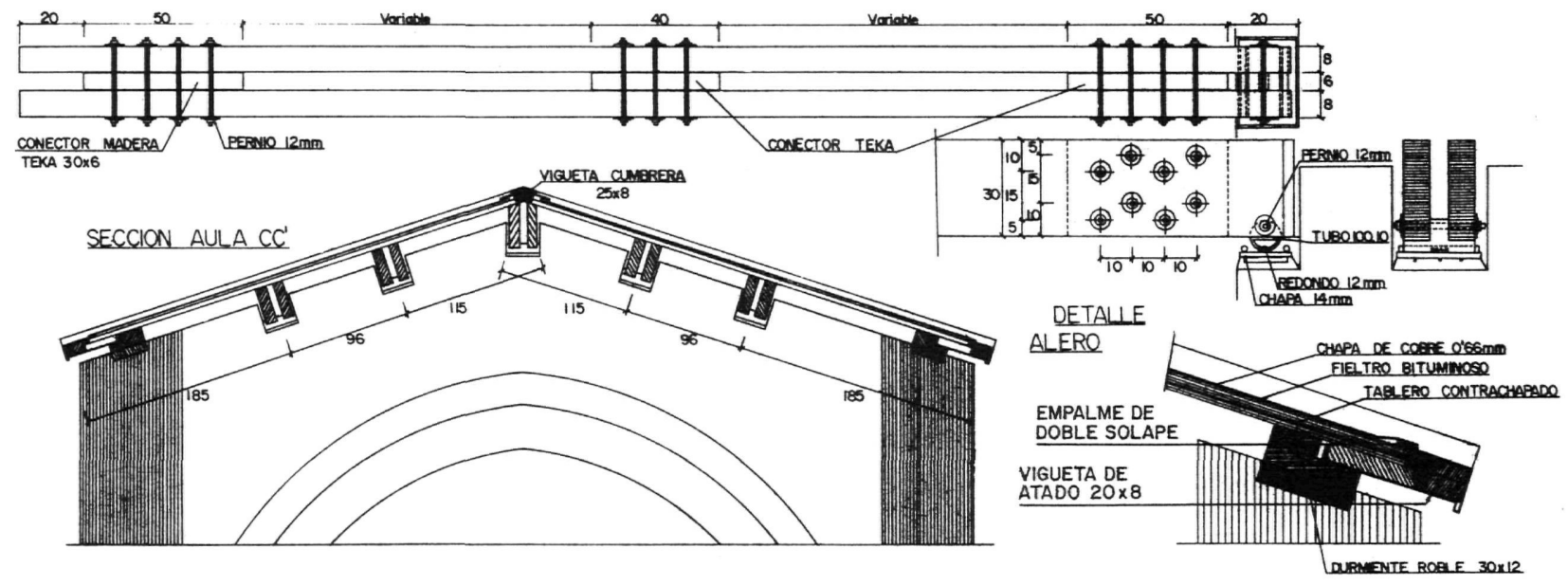

Detalles constructivos de la cubierta del aula

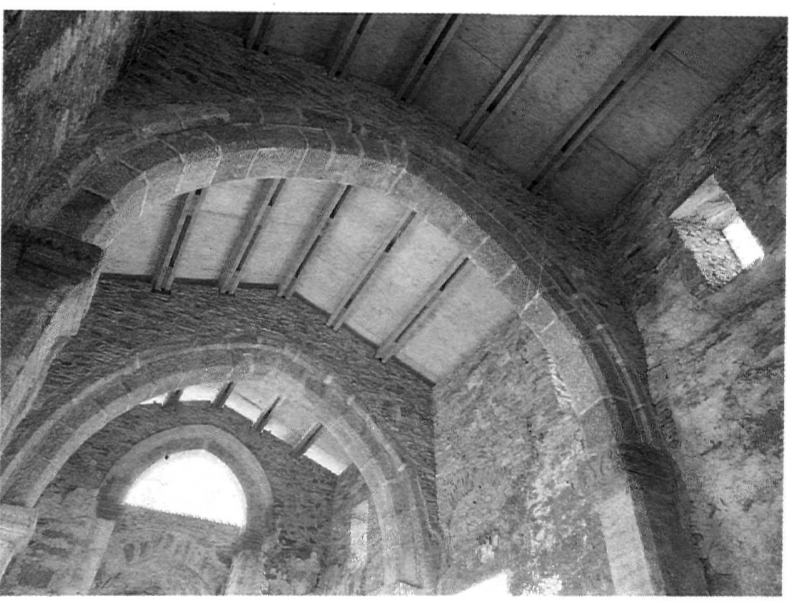

La cubierta del aula.

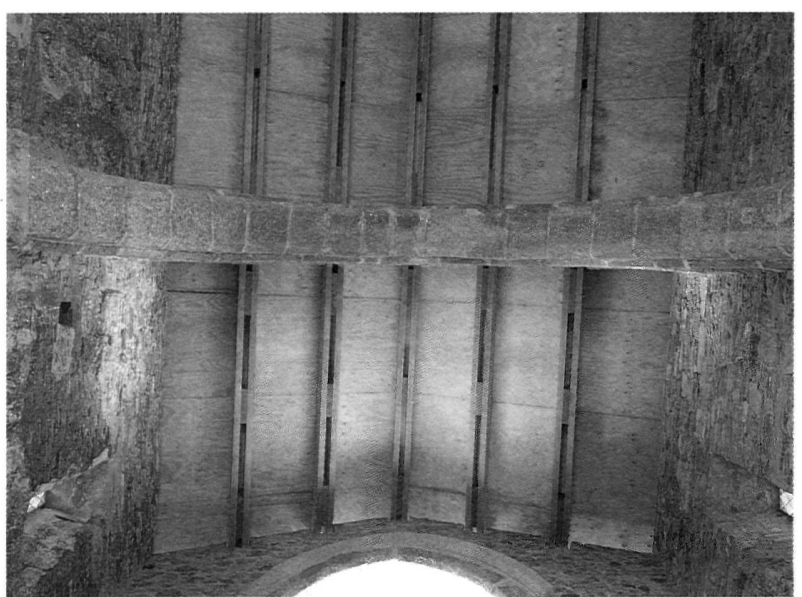

Detalle de la cubierta del aula. 


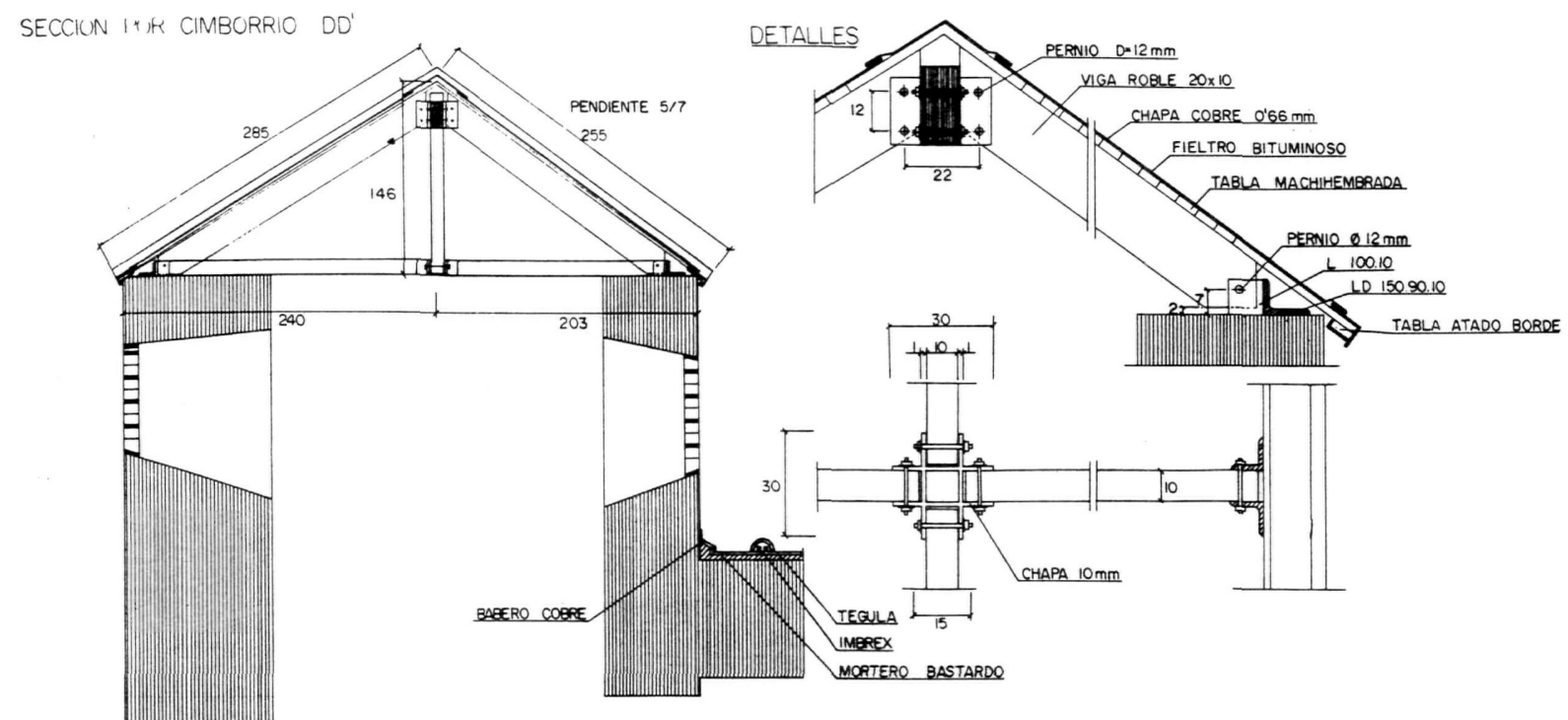

Detalles constructivos de la cubierta de la cabecera

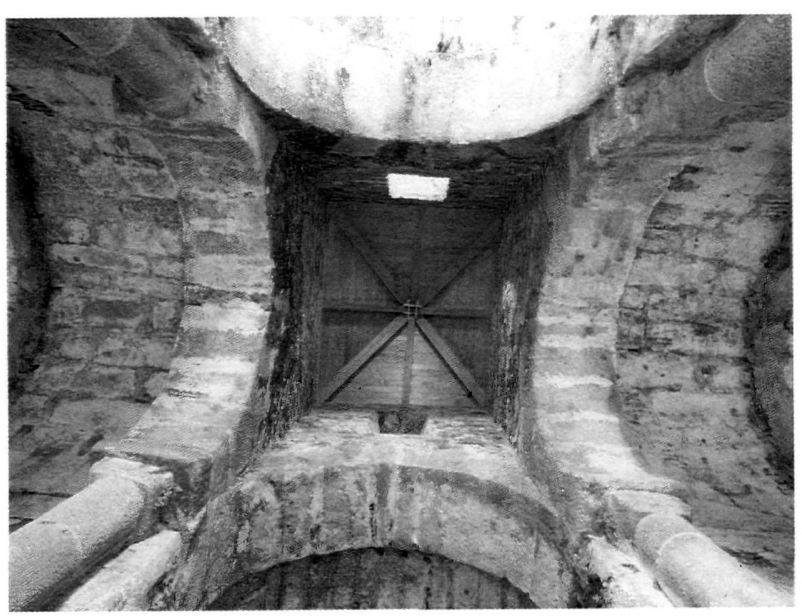

Amadura de la cubierta del cimborrio central

dar a las calles unas dimensiones similares a las de las tegulae de la cubierta visigoda, pero la discordancia entre la medida de éstas y los formatos comerciales de las chapas de cobre y el elevado costo que ello acarreaba nos hicieron desistir de aplicar esta solución.

Este sistema de cubierta tiene el carácter de elemento sobrepuesto, pues hemos tratado de que todas sus partes queden claramente separadas de las estructuras "murarias". Con ello hemos querido poner más de manifiesto el carácter de elemento nuevo y en cierto modo postizo, a la vez que al no constituir remate de los muros, ponen en evidencia que la altura que éstos alcanzan es hipotética al no haberse conservado en esta parte ningún elemento de remate original. Tal consideración conllevaba el aplicar simi- lar solución a los cimborrios, para los que asimismo carecemos de datos ciertos en cuanto a su altura. La hipótesis a nuestro juicio más plausible es que estos elementos estuvieron también cubiertos con armadura de madera. Por ello decidimos igualmente cubrir los cimborrios con una armadura de madera formada por cuatro vigas diagonales y un tablero de madera contrachapada recubierto con chapa de cobre.

Para el cubrimiento de los espacios abovedados, el problema era claramente distinto puesto que los hallazgos nos permitían saber cuál era el material original empleado, su disposición y forma de colocación, las pendientes de los tejados y la altura de remate de los muros. Por ello tomamos la decisión de hacer en estas zonas unas cubiertas nuevas utilizando el mismo sistema original a base de tegulae e imbricis, sentados directamente sobre un relleno de la parte superior de las bóvedas para formar las pendientes.

En cuanto al pavimento, cuyo sistema original era de opus signinum (mortero de cal con abundante ladrillo machacado y bien alisado en la superficie) decidimos reponer las partes que faltaban con el mismo material marcando la separación entre lo antiguo y lo nuevo con el mismo sistema de introducir en la junta una fina chapa de cobre. En el aula, se han colocado unos sillares con la forma y tamaño de las huellas o de los cimientos de los pilares de las desaparecidas arquerías de separación de las naves, dejando así constancia de la estructura primitiva de esta parte de la iglesia. Estos sillares sólo levantan 


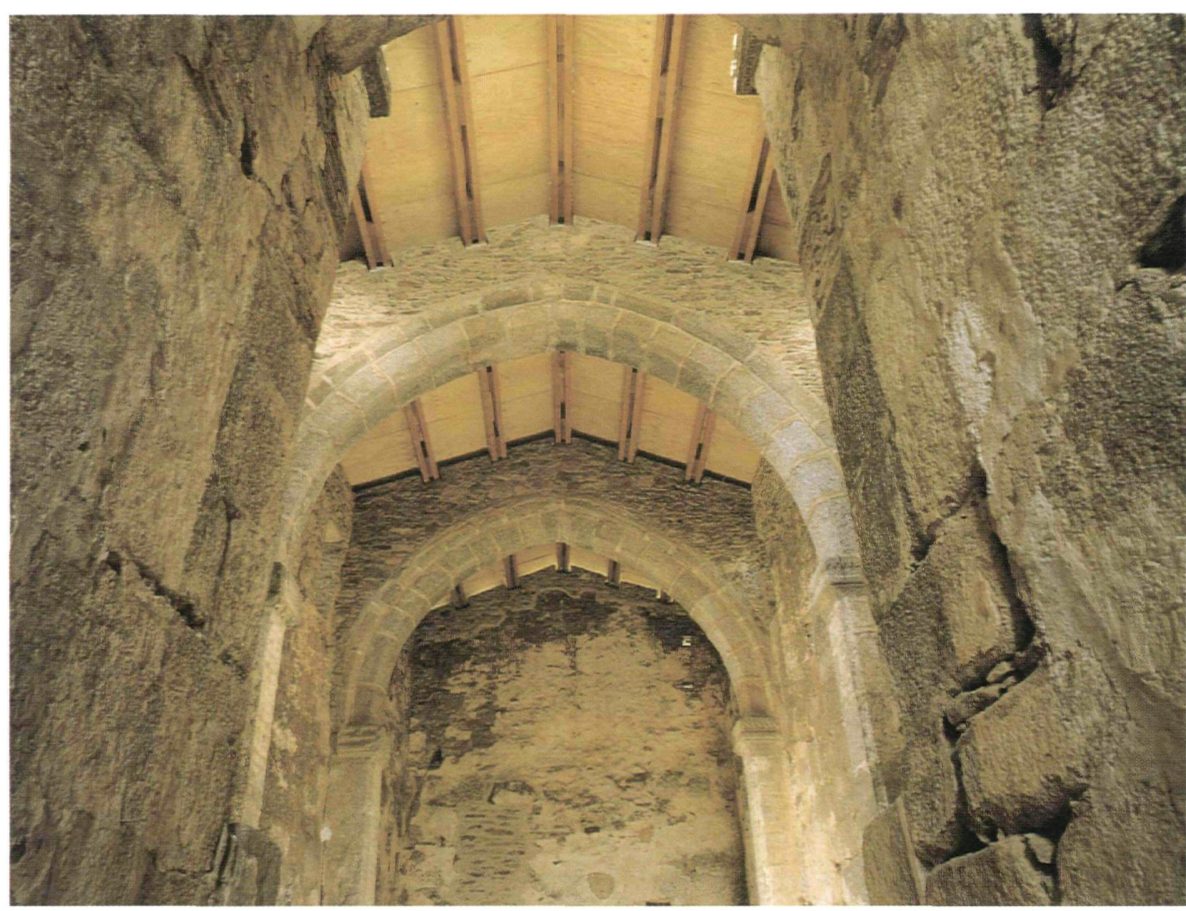

Alzado de la cabecera de la iglesia

del suelo unos $50 \mathrm{~cm}$, guardando relación con los restos de los pilares que se han conservado visibles.

Para el cerramiento de la Iglesia también hemos acudido a elementos de diseño actual, aunque inspirados formalmente en soluciones antiguas. Hay claros indicios de que las ventanas tuvieron celosías, pues en las jambas se aprecian cajeados para su colocación, aparte de haber sido ésta la solución generalmente utilizada. Las puertas de comunicación del aula con los pórticos no parecen haber tenido ningún sistema de cierre. Las de paso desde el crucero a las salas laterales (hoy desaparecidas al igual que los pórticos) parece que tuvieron hojas que se abrían hacia el exterior de la iglesia. Como sistema de cerramiento que permita impedir el acceso no deseado al interior, se han diseñado rejas formadas por pletina dispuesta en rombo de apariencia y tamaño de huecos que recuerdan las celosías imbricadas tan usuales en el mundo clásico y visigodo y que perviven también en época omeya. En las puertas se han colocado rejas practicables con igual diseño y articuladas de modo que afecten mínimamente a las jambas. Durante la realización de la mayor parte de esta fase, se protegieron las zonas excavadas y los vestigios arqueológicos mediante un fieltro textil y una capa de arena estéril que fueron eliminados al concluir los trabajos.

\section{Ficha Técnica}

$\begin{aligned} & \text { Restauración } \\ & \text { arquitectónica: Dr. Antonio Almagro Gorbea. }\end{aligned}$
\[ \begin{array}{l}\text { Escuela de Estudios Árabes, CSIC. Granada } \\ \text { Pablo Latorre González-Moro y Leandro Cámara Muñóz. Madrid. }\end{array} \]
$\begin{aligned} & \text { Financiación: Dirección General de Patrimonio, Consejería de Patrimonio } \\ & \text { arqueológica: Dr. Luis Caballero Zoreda, Centro de Estudios Históricos, } \\ & \text { Cultural, Junta de Extremadura. }\end{aligned}$

